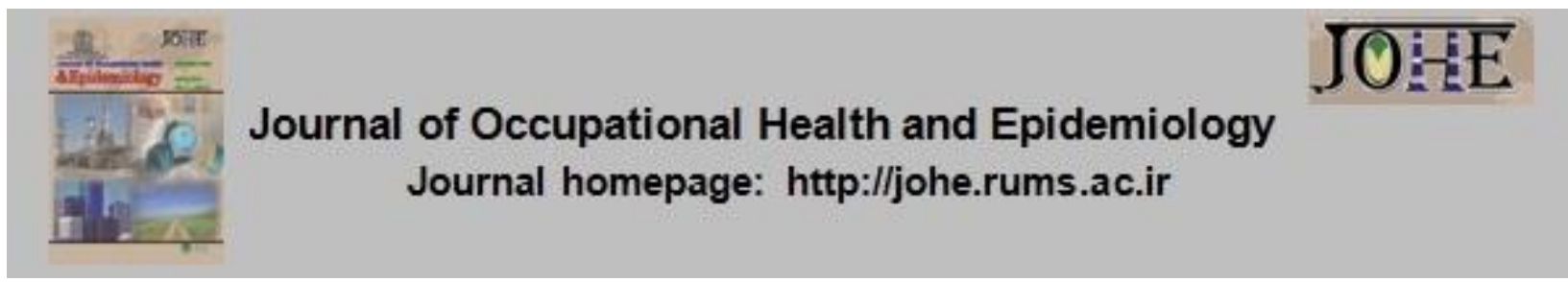

\title{
The association between workplace spirituality and Job Stress with occupational ethics through mediating role of Job Enthusiasm among nurses in Zahedan City, 2017
}

\author{
Reza Norouzi ${ }^{1}$, Shahriar Dargahi ${ }^{2,}$, Nader Aeyadi $^{3}$, Mahdieh Sarhaddi $^{1}$ \\ 1- Faculty Member, Payame Noor University, Tehran, Iran. \\ 2- PhD Student in Counseling, University of Mohaghegh Ardabili, Ardabil, Iran. \\ 3- MA in Family Counseling, Faculty of Psychology and Educational Sciences, Kharazmi University, Tehran, Iran.
}

\section{Article Info}

* Corresponding authors:

Shahriar Dargahi,

E-mail:

dargahishahriar@gmail.com

Article history

Received: Oct, 2017

Accepted: Dec, 2017

Print ISSN: 2251-8096

Online ISSN: 2252-0902

Peer review under responsibility of Journal of Occupational Health and Epidemiology

\begin{abstract}
Background: Observing ethical principles is a part of nursing occupation and nurses should be aware of the importance of this subject when providing nursing care in order to provide their skills based on occupational ethics. Therefore, this study was conducted with the aim to investigate the relationship between occupational stress and the workplace spirituality with the nurses' occupational ethics through the mediating role of job enthusiasm.
\end{abstract}

Materials and Methods: This was a cross sectional-descriptive study. The study population consisted all man and woman nurses working at hospitals in Zahedan City, Iran. Cluster sampling method was used to select the sample group. A total of 160 nurses were selected as the sample for the study. To collect data, the organizational spirituality questionnaire proposed by Milliman, et al., standard occupational ethics questionnaire by Gregory C. Petty and Expanded Nursing Stress Scale (ENSS) by French et al., and job enthusiasm questionnaire were used. The data were analyzed using path analyzing method.

Results: The present study showed that the job enthusiasm variable plays a mediating role between workplace spirituality and occupational stress with the nurses' occupational ethics $(P<0.001)$. In addition, the positive effect of workplace spirituality (0.277) and negative occupational stress ($0.204)$ was significant on occupational ethics $(P<0.001)$.

Conclusions: The results of the study, in line with other studies, show that occupational stress and workplace spirituality with impact on job enthusiasm can explain the occupational ethics of nurses.

Keywords: Workplace, Spirituality, Occupational Stress, Ethics, Nurses

\section{Introduction}

Occupational ethics refer to the rules and standards for occupational behavior of individuals (1). The ultimate aim of the nursing occupation is to serve human beings and to realize this only through scientific and ethical care and proper communication with the patient. In practice, it is impossible to distinguish between ethics and clinical practice. Therefore, ethical behavior along with the responsibility of nurses can be considered as effective factors in improving and returning the health of patients (2). Nurses are ethically responsible and should be responsive for

(C) The Author(s) 2018. Published by Rafsanjan University of Medical Sciences Press.

All rights reserved. For permissions, please e-mail: johe.rums@gmail.com, johe@rums.ac.ir 
their behaviors (3). Patient care is an important concept and indeed the art of nursing and requires the individual, social, moral, and spiritual ability of the nurse to provide good and ethical care. Based on the nature of nursing, more attention must be paid to care ethics compared to therapeutic considerations. Researches haves shown that there is a negative and significant relationship between the general index of occupation ethics and all its dimensions with occupational stress (4).

Today, occupational stress can be observed in all occupations and has created many problems for individuals and organizations. Meanwhile, National Institute for Occupational Safety and Health (NIOSH) has introduced nursing at the top of 40 occupations with a high incidence of stressrelated illnesses, and believes that nursing is at the head of high-level careers among healthcare occupations $(5,6)$. Nursing occupational stress has a high level of physical and mental illness for nurses and affects their mental well-being (7).

Occupational stress and its outcomes make nurses follow their work responsibilities with disappointment and lack of motivation (8). This healthcare team have close contact with patients, and hence, they are constantly faced with ethical decisionmaking (9).

Workplace spirituality describes the experience of employees who perform their tasks with energy, are internally satisfied with their work, understand the meaning and purpose of their work, and feel that they have effective communication with their colleagues (10). The study of workplace spirituality can be a powerful positive force for the lives of individuals and may make them work longer, more balanced and meaningful. Moreover, Millman et al. (11) argued that workplace spirituality improves employee attitudes including, increased job satisfaction, job engagement, decreased workplace leave intentions, and increased organizational commitment. All of these directly and indirectly improve organizational performance, profitability and effectiveness. Researches suggest that there is a relationship between occupational ethics and spirituality in the occupational performance of nurses $(12,13)$.

Job enthusiasm indicates the amount of incentives and interests of employees in their organization's identity. Therefore, the job enthusiasm can be considered as the amount of energy that a person spends for his or her job; it can also be taken into account as the work effectiveness (14). In fact, job enthusiasm as a positive phenomenon in the workplace, is very significant for the absence of negative consequences like occupational burnout, error and sabotage in the job, and lack of work from the point of view of conservation of resources (15).

Given that job enthusiasm is defined as a cognitive commitment to the organization, or the amount of purely endearing work that the individual shows in his/her work environment, job enthusiasm can be linked to other variables including occupational ethics (16). Zahed et al. (17) concluded that occupational ethics had a direct effect on job enthusiasm. The support of colleagues and supervisors, feedback from performance, diversity of duty and autonomy and learning opportunities are among the sources that increase the employee's job enthusiasm (17). Job enthusiasm plays a mediating role in the relationship between the psychological climate, perceived organizational support and organizational outcomes like job performance. Moreover, job enthusiasm is correlated with nursing stress (18).

When organizational behavior is morally weak, the cost of performance increases explicitly and implicitly. These costs can be identified in different areas of the organization including low productivity, slowness of organization dynamics, lack of transparency and congestion of communications. Based on the viewpoints 
of the researchers and experts, the factors like structure, technology and equipment are not the only reasons for the success of organizations, rather immaterial and spiritual factors have also been effective in this issue (19). Therefore, considering the importance of occupational ethics in increasing the efficiency and effectiveness of manpower, especially in health care and hospital climate, and due to the ignorance of the indirect effect of workplace spirituality and occupational stress on occupational ethics among nurses in research literature, the present study was carried out to determine the relationship between occupational stress and workplace spirituality with the occupational ethics of nurses through the mediating role of job enthusiasm. In this study, the following hypotheses were investigated: 1workplace spirituality and occupational stress have a direct impact on the occupational ethics of nurses. 2- Working spirituality affects the occupational ethics of nurses by increasing job enthusiasm. 3Occupational stress affects nurses' occupational ethics through reducing job enthusiasm.

\section{Materials and Methods}

This was a cross sectional-descriptive study conducted on all nurses working at hospitals in Zahedan City in 2017. The convenient sampling method was used to select the subjects; therefore, with the permission and collaboration of 6 existing hospitals, 30 subjects were selected from each hospital, hence a total of 180 nurses were selected as the study population. This number of subjects was selected to represent the real community. Acording to Anderson (20), the minimum number of the subjects should be 150 individuals. Researchers attended hospitals after the data collection questionnaires were presented to the nurses. $90 \%$ of the total number of the distributed questionnaires
(200) was filled completely by the respondents.

The study inclusion criteria included working at the hospital for at least 2 years and lack of the psychiatric problems. In addition, the exclusion criteria were the absence of any of these two cases.

By following ethical considerations like confidentiality of information and informed consent of individuals, self-report questionnaires were completed by nurses.

Data were collected using the Nursing Stress Scale (NSS) questionnaire presented by Gray-Toft and Anderson (21). This questionnaire consisted of 34 questions in the dimensions of patient suffering and death, involvement with physicians, lack of readiness, lack of support, involvement with other nurses, pressure, and uncertainty about treatment with $7,5,3,3,5,6$, and 5 questions, respectively. The questions of this tool were based on Likert scale with four options as not stressful, rarely stressful, sometimes stressful, and always stressful with a score of $1,2,3$, and 4, respectively. The range of scores was 34-136 and the scoring was as follows: scores less than or equal to $68,69-103$, and equal to 104 or higher indicated low, average and high stress, respectively. In a study by Rezaee (22), the reliability of the test was obtained through Cronbach's alpha coefficient as $0.74,0.76,0.76,0.76,0.74,0.74$, and 0.74 for dimensions of patient's suffering and death, conflict with the doctor, lack of adequate readiness, lack of adequate support resources, high working volume, conflict with other nurses, and uncertainty about treatment, respectively.

The occupational ethics questionnaire was developed by Gregory C. Petty and includes 23 items (23). The four dimensions of occupational ethics from Petty's point of view were: attachment and interest in work, perseverance and seriousness in work, healthy and human relationships at work, and collective spirit and participation in the work with score ranges of 1-6, 7-12, 13-17, 
and $18-23$, respectively. This questionnaire was based on the Likert scale with options as completely disagree, disagree, neutral agree, and completely agree, with a score of $1,2,3,4$, and 5 , respectively. For the whole scale, the minimum and maximum score was 23 and 92, respectively. Higher scores reflect more occupational ethics. This questionnaire had the necessary content validity due to the appropriate theoretical foundation and confirmation of the experts. There was no reverse questions in the questionnaire. In the study by Salehi et al. (24), the face, content and structure validity of the questionnaire was evaluated and its reliability was confirmed by calculating the Cronbach's alpha coefficient.

The job enthusiasm questionnaire contained 18 questions with the aim to measure the degree of job enthusiasm among the individuals in terms of the dimensions of enthusiasm, endowment for work, and attraction in work (25). The response scale of the questionnaire was based on Likert scale with options of very low, low, sometimes, high, and very high with scores of $1,2,3,4$, and 5 , respectively, however, this scoring method was inverse in questions 5,10 , and 17. For the whole scale, the minimum and maximum score was 18 and 90, respectively. To total score of the questionnaire was obtained summing up the total scores of all questions together. Higher scores reflected more enthusiasm of nurses at work and vice versa (25). In the study by Kabirzadeh $(26$,$) the content$ validity of this test was verified and confirmed by the experts. Furthermore, the reliability of the questionnaire was calculated using Cronbach's alpha coefficient. The Cronbach's alpha coefficient was obtained as $0.69,0.71$, and 0.65 for the dimensions of job enthusiasm, endowment for work, and attraction in work, respectively.

The organizational spirituality questionnaire proposed by Milliman, et al. (27) was used in order to measure the organizational spirituality. This questionnaire included 20 questions and 3 components. The scoring method in this questionnaire was based on the five-point Likert scale as completely disagree to completely agree with a score range of 1 to 5 , respectively. For the whole scale, the minimum and maximum scores were 20 and 100, respectively. Moreover, this questionnaire has been used in various studies so far, and the calculated Cronbach's alpha coefficient was 0.87 for this scale (28).

The data were analyzed using descriptive statistics and path analyzing method and the 18 Amos software. Moreover, the Kolmogorov-Smirnov (K-S) test was used to ensure the normal data distribution. Furthermore, a significance level of 0.05 was considered.

\section{Results}

Among all the participants in the study, 96 (53.33) and 84 (46.67) were women and men, respectively. In addition, 117 (65.00) and 63 (35.00) of the subjects were married and single, respectively. 36 (20.00) and 144 (80.00) of the participants worked in the emergency department and the nongovernmental sector, respectively. The mean and standard deviation (SD) of the variables studied and their dimensions have been presented in table 1 . The K-S test results indicated that the scores were in normal levels.

Before examining the research hypotheses in order to obtain more information, the role of the predictor of organizational spirituality, and occupational stress and enthusiasm was studied on occupational ethics. The correlation coefficient of the organizational spirituality, and occupational stress and enthusiasm with professional ethics was $R$ $=611$, indicating a high correlation between these variables. This correlation coefficient showed that $47.60 \%$ of the variance of the professional ethics involved in the study 
was explained by the variables of organizational spirituality, and occupational stress and enthusiasm. The role of all three variables was also significant in predicting the occupational ethics $(P<0.001)$. The path analysis should be confirmed in order to examine the mediating role of job enthusiasm variables among occupational stress and organizational spirituality with the occupational ethics.

Table 1: Mean and standard deviation (SD) of the studied variables among nurses working in hospitals in Zahedan City, Iran

\begin{tabular}{ccccc}
\hline Variables & \multicolumn{4}{c}{ Mean \pm SD } \\
\hline Male & Female & Minimum & Maximum \\
\hline Workplace spirituality & $44.56 \pm 4.09$ & $45.21 \pm 4.33$ & 22 & 71 \\
\hline Occupational stress & $83.61 \pm 3.16$ & $86.90 \pm 4.63$ & 37 & 120 \\
\hline $\begin{array}{c}\text { Occupational } \\
\text { enthusiasm }\end{array}$ & $34.79 \pm 3.02$ & $33.31 \pm 5.51$ & 20 & 61 \\
\hline Occupational ethics & $58.61 \pm 3.21$ & $63.42 \pm 5.89$ & 50 & 90 \\
\hline
\end{tabular}

As shown in figure 1, all three path coefficients are significant $(P<0.001)$. In other words, organizational spirituality and occupational stress have a direct effect on occupational ethics. Moreover, the organizational spirituality had an indirect effect on occupational ethics with increasing job enthusiasm. Occupational stress affected the occupational ethics indirectly with reducing job enthusiasm. The fit indices of the model are presented in table 2 to confirm the proposed model.

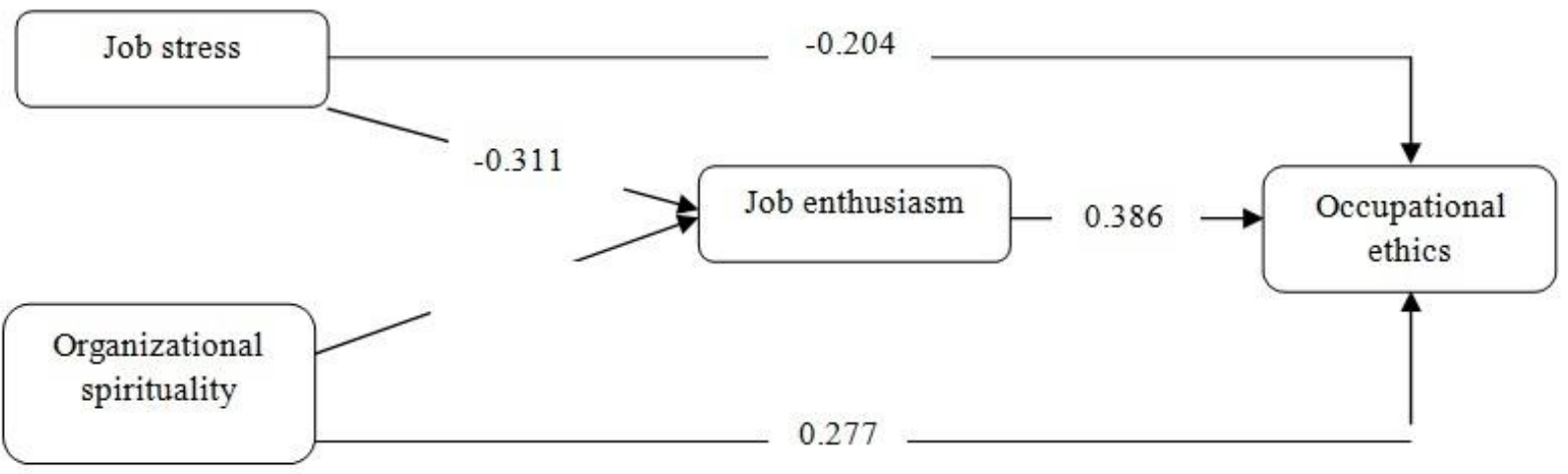

Figure 1: Fitted model for mediating role of job enthusiasm in the relationship between organizational spirituality and occupational stress with occupational ethics (All three path coefficients were significant) $(P$ $<0.001)$

As shown in table 2, the value of chi-square index is not significant $(P>0.050)$, and all fit indices of the model have also reached the reasonable fit criterion. Goodness of fit index (GFI) and comparative fit index (CFI) are above 0.90 , which are reasonable for model fitness. The root mean square error of approximation (RMSEA) was also 0.056 which is reasonable.

Regarding the fit indices of the model, it can be said that the proposed model has reasonable fitness and the study hypotheses have been confirmed. Therefore, according to these findings, it can be concluded that job enthusiasm plays a significant mediating role in the relationship between organizational spirituality and occupational stress with occupational ethics. 
Table 2: Model fit indices

\begin{tabular}{ccccccc}
\hline Index & $\mathbf{X}^{2}$ & $\mathbf{P}$ & GFI & AGFI & CFI & RMSEA \\
\hline Value & 1.905 & 0.206 & 0.991 & 0.958 & 0.991 & 0.056 \\
\hline
\end{tabular}

GFI: Goodness-of-fit; AGFI: Adjusted goodness-of-fit index; CFI: Comparative fit index; RMSEA: Root mean square error of approximation

\section{Discussion}

The first finding of the study indicates that spirituality has a direct effect on occupational ethics. This result is consistent with the results presented in (29). Since, individuals with high workplace spirituality are more responsible, moral and hardworking, and these attributes are associated with hope for the future and interest and commitment to work.

The second finding of the research suggests that occupational stress and workplace spirituality has a direct effect on occupational ethics. The results of the studies by Soleimani (30) and Burke (31) and (13) are in line with those of the present study. Stress is one of the most acute problems of today's organizations which endangers the physical and mental health of the workforce and expose heavy burden on organizations. Regarding the stressful nature of nursing occupation and its effect on burnout due to this occupation (32), it can be indicated that the perception of these stressful situations and the occurrence of burnout can affect the work ethics of nurses. Moreover, it has meaning in working alongside stressors in work and work environment, identifying and preserving real values in work leads to ethical and professional principles in organizations.

Another finding of the study suggests that the job enthusiasm has a direct effect on occupational ethics. The higher job enthusiasm among the nurses leads to a higher degree of occupational ethics. Job enthusiasm among the employees is a factor that adds value to the organization and involves conscious and voluntary work of the staff to increase their career level, which results in tasks being carried out in less time and with more interest. This could support the role of enthusiasm in improving nurses' professional ethics (14). Furthermore, despite the inner motive for work and its satisfaction, the values of the organization are maintained without supervision of others. Therefore, the direct effect of job engagement on professional ethics seems natural.

Regarding the findings for the effect of occupational stress and workplace spirituality on nurses' occupational ethics through job enthusiasm, it can be argued that nurses with high spirituality in work have high interactions with colleagues and feel pleasure from work and use of full individual power in accordance with the goals and values of the organization. These features will automatically enhance their potential capabilities in the workplace, hence individuals perform their tasks enthusiastically and with the pleasure. The enthusiastic nurses are not only loyal, consistent with organizational goals and values, but also have a strong incentive and are struggling with more enthusiasm.

Burke (30) also stated the consequences of occupational stress including reduction of adherence to organizational ethics, resorting to behaviors to avoid work responsibilities, interruptions in effective communication and emotional interruption with the client. In a study by Marchese et al. (33), it was also shown that employees need to make good choices in balancing work demands and family responsibilities; otherwise, in addition to tolerating stress and tension, they will experience moral degradation. Regarding the sources of nurses' occupational stress and the nature 
of the stressful work of nursing and its effect on nursing job burnout (7), it can be concluded that stressful conditions and the resulting burnout and reducing job enthusiasm can affect nurses' occupational ethics. In general, it can be said that with recognizing the spirituality level in the workplace and occupational stress experienced by nurses, it is possible to predict the extent of their occupational ethics, either directly or through job enthusiasm. The specificity of subjects to nurses in Zahedan is one of the most important limitations of the present research. Therefore, it is suggested that similar researches be conducted in other instances, especially vulnerable businesses.

\section{Conclusion}

Predictive variables can contribute to changes in nurses' occupational ethics. Stress management training, having meaning or purpose in the job and increasing job enthusiasm result in improved nurses' occupational ethics. Therefore, it is suggested to make some plans for reducing nurses' occupational stress and increasing workplace spirituality in order to increase their willingness and enthusiasm for addressing patients' problems and concerns in the form of occupational ethics.

\section{Acknowledgements}

The authors express their sincere thanks to the all nurses working in hospitals in Zahedan City and all employees for their support and contribution to conduct this research.

Conflict of interest: None declared.

\section{References}

1. Rafee Z, Bibak A, Hoseinee S, Azodi F, Jahanpour F. Professional ethics in nursing practice from the perspective of the patients hospitalized in teaching hospitals of Bushehr during 2015. Medical Ethics and History of Medicine 2016; 9(2):80-9.

2. Mohammadi S, Nakhaei N, Borhani $F$, Roshanzadeh M. Moral intelligence in nursing: a cross-sectional study in East of Iran. Medical Ethics and History of Medicine 2013; 6(5):57-66.

3. Akter B, Chaowalit A, Nasae T. Moral behaviors of nurse supervisors expected and perceived by nurses in Bangladesh. Paoer presented at: The $2^{\text {nd }}$ International Conference on Humanities and Social Sciences; 2010 April 10; Faculty of Liberal Arts, Prince of Songkla University, Thailand.

4. Feghhi Farahmand $\mathrm{N}$, Zanjani $\mathrm{S}$. The examination of relationship between employees' conceptions from dimensions of work ethic with job satisfaction and Job stress (Case study: technical training organization of Tabriz). Journal of Sociology 2013; 5(18):103-18.

5. Pouraboli B, Esfandiari S, Ramezani T, Miri $S$, Jahani $Y$, Sohrabi N. Effectiveness of their teaching skills to reduce stress job psychological empowerment of nursing staff in intensive care unit in the center of Shahid Rajaee 2013. Journal of Clinical Nursing and Midwifery 2016; 5(1): 23-35.

6. Hashemi T, Golparvar M. The role of perceived organizational support on relationship between job stress and emotional exhaustion with turnover among nurses. Journal of Clinical Nursing and Midwifery 2016; 4(4):29-39.

7. Karimi L, Leggat SG, Donohue L, Farrell G, Couper GE. Emotional rescue: the role of emotional intelligence and emotional labour on well-being and job-stress among community nurses. J Adv Nurs 2014; 70(1):176-86.

8. Salajeghe S, Farokhian A. Job stress and work ethics. Indian Journal of Fundamental and Applied Life Sciences 2015; 5(S1):32539.

9. Poladi F, Atashzade F, Abaaszade A, Moslemi A. The correlation between moral distress and burnout in nurses working in educational hospitals of Shahid Beheshti University of Medical Sciences during 2013. Medical Ethics and History of Medicine 2015; 8(4):37-45.

10. Ashmos DP, Duchon D. Spirituality at work: a conceptualization and measure. Journal of Management Inquiry 2000; 9(2):134-45.

11. Milliman J, Czaplewski AJ, Ferguson J. Workplace spirituality and employee work attitudes: an exploratory empirical assessment. Journal of Organizational Change Management 2003; 16(4):426-47. 
12. Canda E, Nakashima M, Furman LD. Ethical considerations about spirituality in social work: insights from a national qualitative survey. Families in Society: The Journal of Contemporary Social Services 2004; 85(1):27-35.

13. Bond J. Professional ethics and corporate social responsibility. Process Saf Environ Prot 2009; 87(3):184-90.

14. Frank FD, Finnegan RP, Taylor CR. The race for talent: retaining and engaging workers in the 21st century (2004). Human Resource Planning [Internet]. 2004 [cited 2004]; 12-25. Available from:

http://citeseerx.ist.psu.edu/viewdoc/downloa d;jsessionid=BF570D4A56BC6A34FD0AD00 $A 3918 B 859$ ?doi=10.1.1.514.4132\&rep=rep1 \&type $=$ pdf

15. Schaufeli, WB, Bakker AB. Job demands, job resources, and their relationship with burnout and engagement: a multi-sample study. J Organ Behav 2004; 25(3):293-315.

16. Tims M, Bakker AB, Derks D. Development and validation of the job crafting scale. $J$ Vocat Behav 2012; 80(1):173-86.

17. Zahed Babelan $A$, Gharibzadeh $R$, Mortezazadeh AA, Dadjou A. The role of managers' professional ethics in organizational excellence; with the mediation of job engagement. Journal of Bioethics 2017; 6(22):59-70.

18. Mohammadzadeh A, Vahedi M, Ghorbani K, Jafari E. Assessing the role of personality traits and job engagement in predicting nursing stress among orthopedic nurses in Shohada Hospital of Tabriz. Journal of Hospital 2016; 15(1):69-76.

19. Kegans L. Occupational work ethic differences: implications for organizational diversity initiatives in health care organizations. Performance Improvement Quarterly 2009; 22(3):83-94.

20. Anderson JC, Gerbing DW. Structural equation modeling in practice: a review and recommended two-step approach. Psychol Bull 1988; 103(3):411-23.

21. Gray-Toft P, Anderson JG. The nursing stress scale: development of an instrument. J Behav Assess 1981; 3(1):11-23.

22. Rezaee N, Behbahany N, Yarandy A, HosseiniF. Correlation between occupational stress and social support among nurses. Iran Journal of Nursing 2006;19(46):71-8.

23. Pettijohn Ch, Pettijohn L, Taylor AJ. Salesperson perceptions of ethical behaviors: their influence on job satisfaction and turnover intentions. J Bus Ethics 2008; 78(4):547-57.

24. Salehi M, Dadgar Z. The relationship between professional ethics and organizational Commitment From the viewpoint of nurses in Imam Khomeini hospital in Sari. Bioethics Journal 2016; 6(20):33-46

25. Schaufeli WB, Salanova M, González-Romá $\mathrm{V}$, Bakker $\mathrm{AB}$. The measurement of engagement and burnout: a two sample confirmatory factor analytic approach. J Happiness Stud 2002; 3(1):71-92.

26. Kabirzadeh $\mathrm{K}$. Examines the relationship between customer satisfaction and enthusiasm for working with Maskan Bank branches in llam province. [MSc thesis]. Ilam: Islamic Azad University of Ilam; 2014

27. Milliman J, Czaplewski AJ, Ferguson J. Workplace spirituality and employee work attitudes: an exploratory empirical assessment. Journal of Organizational Change Management 2003; 16(4):426-47.

28. Azadmarzabadi E, Hoshmandja M, Poorkhalil M. Relationship between organizational spirituality with psychological empowerment, creativity, spiritual intelligence, job stress and job satisfaction of university staff. International Journal of Behavioral Sciences 2012; 6(2):181-7.

29. Mohajeran B, Shohoodi M . Structural modeling of relationship between professional ethics and Spirituality at work with social responsibility among nurses in the public hospitals in Kermanshah city. Quarterly Journal of Nursing Management 2014; 3(2):20-9.

30. Soleimani N, Abbaszadeh N, Niazazari B. The relationship work ethics to staffs' job satisfaction and job stress in vocational and technical education organization in Tehran. Quarterly Journal of New Approach in Educational Administration 2012; 3(1):21-36.

31. Burke RJ. Some antecedents and consequences of work-family conflict. J Soc Behav Pers 1988; 3(4):287-302.

32. Farhadi A, Movahedi Y, Nalchi M, Daraei M, Mohammadzadegan $R$. The relationship between work-family conflict, burnout dimensions and intention to leave among female nurses. Iran Journal of Nursing 2013; 26(84):34-43.

33. Marchese MC, Bassham G, Ryan J. Workfamily conflict: a virtue ethics analysis. J Bus Ethics 2002; 40(2):145-54. 